\title{
Isolation and expression of scabrous, a gene regulating neurogenesis in Drosophila
}

\author{
Marek Mlodzik, Nicholas E. Baker, and Gerald M. Rubin
}

Howard Hughes Medical Institute and Department of Molecular and Cell Biology, University of California at Berkeley, Berkeley, California 94720 USA

\begin{abstract}
Mutations in the Drosophila scabrous (sca) gene affect eye and bristle development, leading to irregular spacing of ommatidia and bristle duplications in the adult fly. We have cloned the sca gene by P-element tagging. The sca transcription unit is $12 \mathrm{~kb}$ and consists of four exons that are joined in a 3.2-kb mRNA. In an enhancer trap screen we have isolated several $\mathrm{P}[$ lacZ $]$ insertions close to the sca transcription start site. We have examined the expression pattern of sca by in situ hybridization to sca transcripts, by $\beta$-galactosidase localization in the $P[$ lacZ $]$ lines, and by immunocytochemistry with an anti-sca antiserum. During embryogenesis, sca is expressed in a dynamic pattern associated with neural development. During imaginal development, sca is mainly expressed in the $\mathbf{R 8}$ photoreceptor precursor cells in the eye imaginal disc and in sensory organ precursor cells in other discs. In the wing disc, sca expression is coextensive with the anlagen for bristles and is controlled by genes of the achaete-scute complex. Based on its loss-of-function phenotype, expression pattern, and the predicted structure of its product, a secreted peptide with homology to the fibrinogen gene family, we propose that sca encodes a signal involved in lateral inhibition within individual domains of the developing nervous system.
\end{abstract}

[Key Words: scabrous; Drosophila; neurogenesis; pattern formation; enhancer trap lines; genetic interactions]

Received July 9, 1990; revised version accepted August 30, 1990.

During the development of the fly's adult peripheral nervous system (PNS) in the imaginal discs, it is thought that regions that will give rise to sensory organs are first defined within each imaginal disc. Subsequently, within each of these neurogenic regions some cells become neural precursors, whereas others develop as supporting cells or epidermal cells. These developmental decisions are governed by cellular interactions (Held and Bryant 1984; Garcia-Alonso and Garcia-Bellido 1988; Ghysen and Dambly-Chaudiere 1988). In particular, within each neurogenic group of cells, those cells that become sensory organ precursors appear to inhibit their neighbors from also adopting a neural fate by a process known as lateral inhibition (Wigglesworth 1940; Richelle and Ghysen 1979; Held and Bryant 1984).

Mutations in several genes are known to affect this process and lead to either the loss or gain of sensory organs. Analyses of the genetic hierarchies and molecular features of such genes have revealed features of the molecular mechanisms used in the developmental decision to form a neural precursor cell. For example, the genes of the achaete-scute complex (AS-C; for review, see Ghysen and Dambly-Chaudiere 1988), hairy (h; Rushlow et al. 1989), daughterless (da; Caudy et al.
1988), and extramacrochaetae (emc; Ellis et al. 1990; Garrell and Modolell 1990|, appear to encode proteins that are related to the myc family of transcription factors (Murre et al. 1989). Notch (Kidd et al. 1986; Wharton et al. 1985) and Delta (Vaessin et al. 1987; Kopczynski et al. 1988) encode transmembrane proteins with epidermal growth factor (EGF)-like sequence elements in their extracellular domains. Loss-of-function mutations in genes of AS-C and $d a$ decrease neural development, whereas mutations in Notch, Delta, $h$, and emc lead to excessive neural development.

The scabrous ( $s c a$ ) gene is required for normal development of portions of the adult PNS. Mutations in $s c a$ cause the array of ommatidia in the eye to develop irregularly, leading to abnormally sized and constructed ommatidia (Fig. 1; Morgan et al. 1938). This defect results from failure to establish the proper number and spacing of ommatidial preclusters during the earliest stages of ommatidial assembly (N.E. Baker, M. Mlodzik, and G.M. Rubin, in prep.). In addition, sensory bristles on the adult cuticle are often duplicated in flies homozygous for sca (Fig. 1; Morgan et al. 1938).

Here, we report the isolation of the sca gene by P-element transposon tagging. Using in situ hybridization to 


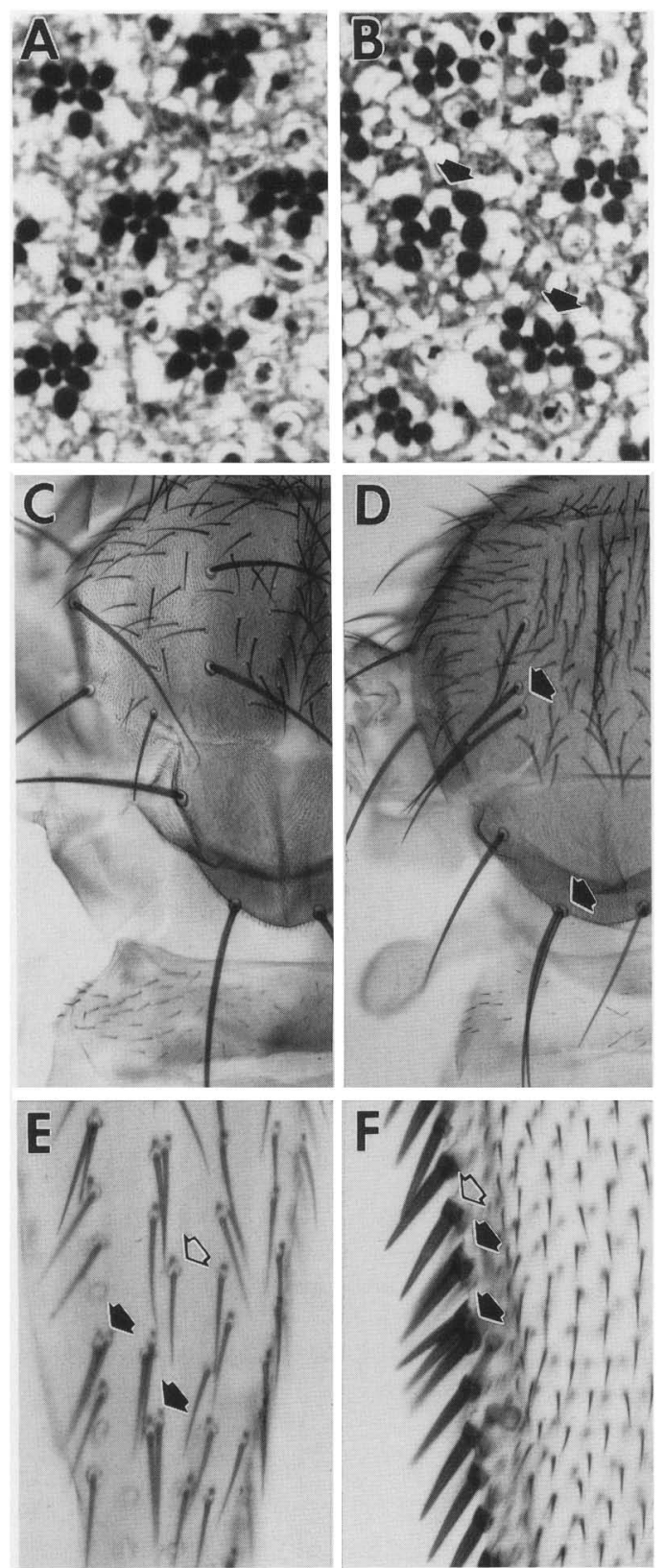

Figure 1. The sca phenotype. Tangential cross section through a wild-type $(A)$ and $s c a^{B P 2}(B)$ eye are shown. Note the irregular arrangement and number of photoreceptors in ommatidia of the mutant sca eye. Ommatidia with more than the normal number of photoreceptors (arrows) are caused by fusions of preclusters due to the more crowded appearance of R8 cells during imaginal disc development (N.E. Baker, M. Mlodzik, and G.M. Rubin, in prep.). In both wild-type and sca eyes, the pigment granules normally present are missing due to the genetic $\mathrm{cn}$ and $b w$ background. $(C)$ Bristles on the notum in a wild-type fly. The left heminotum is shown; anterior is up. $(D)$ Left heminotum of $s c a^{B P 2}$ fly. Note that two bristles have developed in the place of one in several locations. Two duplicated macrochaetae are indicated with arrows. $(E, F)$ Parts of a leg cuticle and the anterior wing margin of a sca fly are shown, respectively. Several bristles on the leg and wing margin are duplicated. Open arrows indicate examples of normal bristles; solid arrows indicate examples of duplicated or triplicated bristles. sca transcripts and anti- $\beta$-galactosidase immunohistochemistry in $\mathrm{P}[\mathrm{lacZ}]$ lines carrying insertions close to the $5^{\prime}$ end of $s c a$, we have surveyed the pattern of sca expression throughout development and studied in more detail the expression in the eye and the wing imaginal discs. In the eye disc, sca is expressed mainly in R8, the first photoreceptor to differentiate. In the wing disc, sca expression was found in the neurogenic regions encompassing the bristle precursor cells. Analyses of $s c a$ expression in various mutant backgrounds suggest that genes of the AS-C activate sca expression. We report elsewhere that $s c a$ encodes a putative secreted protein with homology to the family of fibrinogen-like proteins (N.E. Baker, M. Mlodzik, and G.M. Rubin, in prep.). Taken together, these data suggest that $s c a$ encodes an inhibitory signal used during the process of lateral inhibition during early PNS development in the imaginal discs.

\section{Results}

In sca mutant flies, the eye develops abnormally due to the more crowded appearance of ommatidial preclusters at the earliest stages of eye development, leading to abnormal ommatidia due to fusions of preclusters (Fig. 1A,B; N.E. Baker, M. Mlodzik, and G.M. Rubin, in prep.). In addition, bristles are often found duplicated in adult flies. For example, on the notum of mutant $s c a^{B P 2}$ flies, bristles develop in the normal spatial positions but are often duplicated (cf. Fig. IC and D); and on other parts of the fly body, duplications of innervated bristles are also observed (examples of parts of a leg and the anterior wing margin are shown in Fig. $1 E$ and F). We have examined 16 different mutations at the sca locus (see Materials and methods), and 14 of them resembled $s c a^{B P 2}$ (Fig. 1) when homozygous or in trans to a deficiency, slygesting that this phenotype reflects a complete loss of function of the gene. Moreover, molecular evidence suggested that the $s c a^{B P 2}$ phenotype is due to complete lack of $\mathrm{sca}^{+}$function (see below). Two mutations, $s c a^{K X 2}$ and $s c a^{B X 1}$, are lethal when homozygous. Both are associated with chromosome rearrangements: $s c a^{K X 2}$ with Df(2R)49D1-3;49F1-2 and $s c a^{B X 1}$ with In(2R/49C3-D3; 42. The genotype $s c a^{K X 2} / s c a^{B X 1}$ is viable and resembles $s c a^{B P 2}$, indicating that the lethality of these two chromosomes maps outside the sca locus.

\section{Isolation of the sca gene}

Using deficiencies, Morgan et al. (1938) assigned the $s c a^{1}$ mutation to chromosome bands 49Dl-3 on the right arm of the second chromosome. Meiotic mapping using transposed copies of the white gene confirmed this location, placing $s c a^{1}$ right of a $W^{+}$gene inserted into $49 \mathrm{C} 2-4$ and left of an insert in 49D1-3. An allele isolated after a $\mathrm{P}-\mathrm{M}$ dysgenic cross, $s c a^{B P 1}$, had a $\mathrm{P}$ element inserted at $49 \mathrm{D} 1-3$, and dysgenic reversion of the $s c a^{B P 1}$ mutation correlated with loss of the P-element sequences. A recombinant bacteriophage containing the P-element insertion from $s c a^{B P 1}$ was isolated and used to obtain genomic DNA sequences from the surrounding 49D1-3 re- 
Figure 2. Molecular analysis of the $s c a$ locus. (A) Genomic organization at the sca locus. A restriction map of $\sim 45 \mathrm{~kb}$ of cloned DNA is shown. The start site of transcription was assigned position zero (0). Restriction sites are shown for BamHI (B), EcoRI $(\mathrm{E})$, and $\mathrm{Xba \textrm {I }}(\mathrm{X})$. Above the map, sca alleles that affect the restriction map are indicated. $s c a^{B P 1}$ (a weak allele) is a P-element insertion at coordinate 0 in the map. Other alleles caused by deletions $s c a^{B P 2}, s c a^{B P 3}$, and $s c a^{K X 2}$ are shown. The open portions of the bars indicate the limits of uncertainty in mapping the endpoints of the deletions; the filled portions indicate the minimum extent of deleted DNA. The other breakpoint in $s c a^{K X 2}$ maps to the right of our cloned region (arrow). The allele $s c a^{X L 1}$ affects three different restriction fragments in a complex manner lopen boxes). The intron/exon structure of the gene is shown below the restriction map. The transcription unit spans $\sim 12 \mathrm{~kb}$ and consists of four exons, which are indicated by solid boxes. The $s c a^{B X 1}$ inversion break maps to the left of the cloned region and is therefore not shown on this map, but DNA between 0 and +20 on the map hybridized to the right of the breakpoint on $s c a^{B X 1} /+$ polytene chromosomes (data not shown). As the other inversion breakpoint is in centromeric heterochromatin, it is possible that $s c a^{B X 1}$ affects the $s c a$ gene through a position effect. The cen-

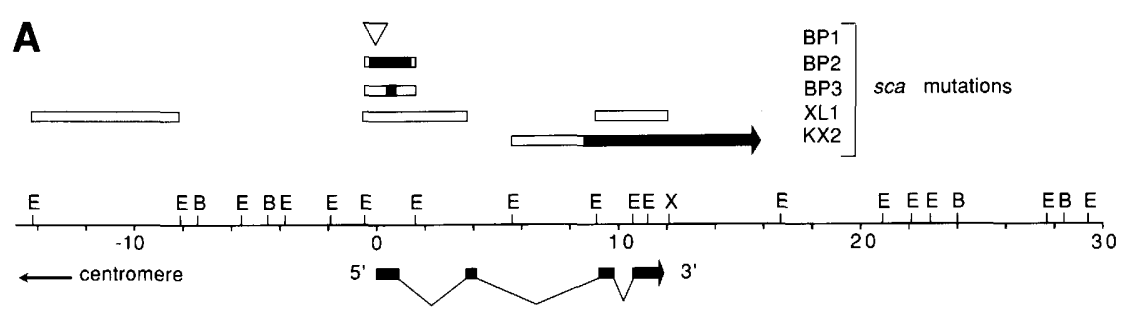

B
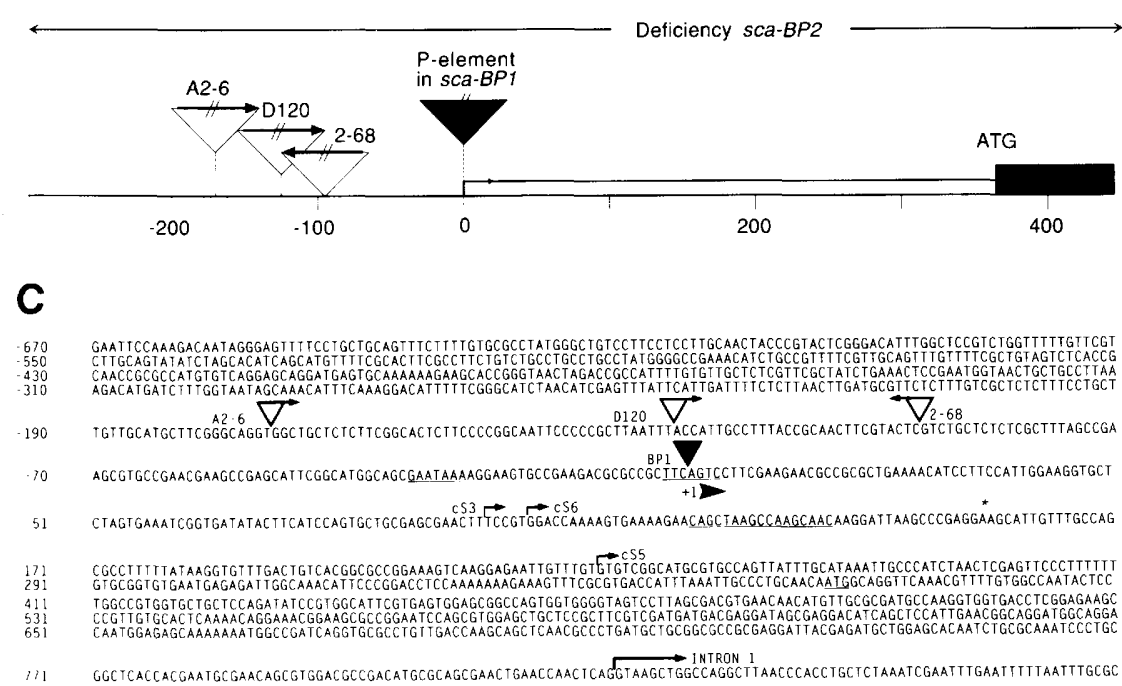

tromere is to the left. $(B)$ Analysis of P-element insertions in the sca promotor region. The sca promotor region between -300 and +425 is shown. The P element in $s c a^{B P 1}$ (inverted shaded triangle) has inserted precisely at position 0 , the start site of transcription (see also $C$ ). Insertion points of the $\mathrm{P}[$ lacZ] elements (isolated in the enhancer trap screen) that were determined by sequencing (A2-6, D120, and 2-68) are indicated by inverted open triangles. The direction of transcription of the P/lacZ fusion gene is indicated by an arrow. Note that all $\mathrm{P}[\mathrm{lacZ}]$ insertions, including two analyzed with DNA blots (K61, T65) and not shown, are upstream of the transcription start site but within $\sim 200$ nucleotides of it. No phenotype was observed in any of these insertions. The sizes of the P-element constructs in this diagram are not drawn to scale; actual size of the P[lacZ] element is $\sim 13 \mathrm{~kb}$. The $s c a$ ORF starts at +377 (shaded box, signal peptide indicated by a solid box; see also $C)$. (C) Genomic nucleotide sequence of the sca promoter region and the first exon. Sequence extending from -670 to +880 is shown; +1 is the start site of transcription, as determined by primer extension experiments. The $5^{\prime}$ extents of the three longest cDNAs, pcS3, pcS5, and pcS6, are indicated. A putative TATA sequence-like element (GAATAAAA at position -32) is underlined, as well as nucleotides complementary to the primer used to map the $5^{\prime}$ end (positions 121-137). Following a 376-nucleotide-long leader, the predicted 774-amino-acid-long ORF (N.E. Baker, M. Mlodzik, and G.M. Rubin, in prep.) starts at the methionine codon at nucleotide 377. We believe that this ATG (underlined) is more likely to be the initiation codon than the first ATG in the same ORF (located at nucleotide 302), because of its better match, 6/7 compared to $3 / 7$, to the translation initiation start consensus (ANNC/AAA/CA/C; Cavener 1987) and because agreement with the Drosophila codon usage preference is above average only after the second ATG. Moreover, immediately following this second methionine codon is a stretch of amino acids that appears to be a signal sequence for secretion. In all cDNAs analyzed, one of the A nucleotides at position 155 or 156 (indicated with an asterisk / is replaced with 19 nucleotides, most likely due to strain differences between wild-type strains used for the genomic and cDNA libraries. The $\mathrm{P}$ allele $s c a^{B P 1}$ has a P-element insertion precisely at the transcription start site (solid inverted triangle) and displays a weak phenotype. The three $\mathrm{P}[\mathrm{lac} Z]$ insertions whose insertion points were determined by sequencing, A2-6, 2-68, and D120, are indicated by open inverted triangles, with arrows indicating the orientation of transcription of the P/lacZ fusion gene. Based on sequence analysis of the $3^{\prime}$ ends of several cDNAs, it appears that the $3^{\prime}$ end of the $s c a$ transcript is in close proximity to the $3^{\prime}$ end of cDNA pcS6. All but one of the cDNAs analyzed ended at a similar point to pcS6, $\sim 27$ nucleotides downstream from a good match to the consensus poly(A) addition signal sequence (AATAAA; N.E. Baker, M. Mlodzik, and G.M. Rubin, in prep.). Nevertheless, none of the cDNAs isolated appears to have a poly(A) tail. One cDNA, pcS5, was found to differ at its $3^{\prime}$ end and extends colinear with the genomic DNA sequence 268 nucleotides past this predicted endpoint, suggesting that not all transcripts use this polyadenylation signal (data not shown). The sequence presented here has been submitted to the GenBank data base under the accession number M37703.

gion (for more details, see Materials and methods).

Figure $2 \mathrm{~A}$ shows a map of $\sim 45 \mathrm{~kb}$ surrounding the $s c a^{B P 1}$ insertion; the position of the $s c a^{B P 1} \mathrm{P}$ element was assigned coordinate zero $(0)$ on the map. DNA blots showed that two other mutations generated by hybrid dysgenesis, $s c a^{B P 2}$ and $s c a^{B P 3}$, were associated with 2- 
and 0.4-kb deletions, respectively, in the same region. The X-ray-induced mutation $s c a^{K X 2}$ was found to be associated with a deficiency of chromosome bands 49D1-3; 49F1-2; sequences were deleted from position approximately $+6 \mathrm{~kb}$ rightward on our map.

DNA sequences from $-670 \mathrm{bp}$ to $+5.7 \mathrm{~kb}$ were used to probe an RNA blot and hybridized to a single poly $(\mathrm{A})^{+}$ RNA species of $\sim 3.2 \mathrm{~kb}$ (Fig. 3). At no stage in development could we detect any other RNA species transcribed from between $-14 \mathrm{~kb}$ and $+12 \mathrm{~kb}$ on the map. RNA blots showed that several of the sca mutations affected the $3.2-\mathrm{kb}$ mRNA. In particular, no transcript was detectable in $s c a^{B P 2} / \mathrm{Sca}^{B P 2}$ homozygotes, indicating that the $3.2-\mathrm{kb}$ RNA is encoded by the sca gene and that the $s c a^{B P 2}$ mutation is a transcript null allele (not shown).

\section{Structure of the sca transcription unit}

DNA sequences $(-670$ to $+6 \mathrm{~kb})$ that hybridized to the $3.2-\mathrm{kb}$ mRNA species were used to probe an eye disc cDNA library. We sequenced the longest isolated cDNA, pcS6, and the corresponding genomic regions. Two additional cDNAs, pcS3 and pcS5, were sequenced at their exon junctions and their $5^{\prime}$ and $3^{\prime}$ ends. All cDNAs analyzed revealed the same splicing pattern and were colinear with the genomic sequence at their termini. The deduced structure of the sca gene is shown in Figure 2A. The $s c a$ transcription unit encompasses $12 \mathrm{~kb}$ and consists of four exons joined to form a 3.2-kb mRNA. Sequence analysis of the $3.2-\mathrm{kb}$ transcript revealed an open reading frame (ORF) that coded for a 774-amino-acid protein. This protein contained a potential secretion signal sequence and had homology to the fibrinogen gene family (N.E. Baker, M. Mlodzik, and G.M. Rubin, in prep.).

Figure $2 \mathrm{C}$ shows part of the sequence of the $2.2-\mathrm{kb}$ genomic EcoRI fragment containing the $5^{\prime}$ end of $s c a$ and the isolated cDNAs. To define the transcriptional start site we have performed primer extension experiments. A 5 '-end-labeled oligonucleotide complementary to nucleotides 121-137 (see Fig. 2C) was annealed to embryonic or imaginal disc poly $(\mathrm{A})^{+}$RNA and extended by using reverse transcriptase. The major extension product was 137 nucleotides long with both RNA sources, placing the transcription start site at the A nucleotide at position 1 (see Fig. 2C). The sequence surrounding this A, TTCAGTC, is a 6/7 match to the Drosophila start site consensus for RNA polymerase II (ATCAG/TTC/T; Hultmark et al. 1986). Thirty nucleotides upstream of this sequence is a potential TATA-box-like sequence element (GAATAAAA; see Fig. 2C). The $5^{\prime}$ extents of the three longest cDNAs isolated and the insertion point of the $\mathrm{P}$ element in the $\mathrm{P}$ allele $s c a^{B P 1}$ have been determined by DNA sequencing (Fig. 2). Remarkably, the $P$ element causing the $s c a^{B P 1}$ mutation has inserted precisely at the $\mathrm{A}$ that marks the start site of transcription.

Isolation of $P[$ lacZ $]$ enhancer trap lines near the sca gene

Study of the structure and expression of the sca gene has been augmented by several $\mathrm{P}[\mathrm{lacZ}]$ insertions near the gene. Recently, it has been shown that in Drosophila a $l a c Z$ fusion gene with a basal promotor often gives rise to a highly specific pattern of lac $Z$ expression due to chromosomal position effects after integration into the genome (O'Kane and Gehring 1987; Bellen et al. 1989; Bier et al. 1989). In such an enhancer trap screen for expression in developing imaginal discs (see Materials and methods|, we have identified five lines that map to position 49D1-3 on the second chromosome and are expressed in the eye imaginal disc. Using DNA blot analysis and/or plasmid rescue (see Materials and methods), we have determined the insertion points of these $P$ elements carrying the $\mathrm{P} / \mathrm{lac} Z$ fusion gene, and all five lines carry a $\mathrm{P}[\mathrm{lacZ}]$ insertion within $\sim 200$ nucleotides of the sca transcription start site (Fig. 2B and C). None of the five lines had a mutant phenotype, suggesting that expression of the endogenous $s c a$ gene was unaffected. For three of these lines, D120, A2-6, and 2-68 we have sequenced the insertion points. In D120 and A2-6, the $\mathrm{P}[$ lacZ) element has inserted 122 (D120) or 169 (A2-6) nucleotides upstream of the transcription start site and orientated so that transcription of the $\mathrm{P} / \mathrm{lacZ}$ fusion gene is the same as sca. In 2-68 the insertion is in the opposite orientation and 93 nucleotides upstream (see Fig. $2 \mathrm{~B}$ and $\mathrm{Cl}$. All five lines display qualitatively the same expression patterns (see below). However, in the line that carries the insertion in opposite orientation with respect to $s c a$ transcription, 2-68, $\beta$-galactosidase is expressed at lower levels. The lack of a phenotype due to the insertion of these elements is surprising, given their large size $(\sim 13 \mathrm{~kb})$ and location within $\sim 200 \mathrm{bp}$ of the transcription start site. The expression patterns of the $\mathrm{P} / \mathrm{lacZ}$ fusion gene and $s c a$ (see below) are governed by one or more enhancer-like elements that are part of the sca regulatory elements. These enhancer-like sequences behave as enhancers in all respects; they can activate transcription on the heterologous $P$ promoter and act independently of orientation and distance; the $\mathrm{P}[\mathrm{lacZ}]$ insertions in the respective lines show no qualitative expression pattern difference when inserted in opposite orientations.

The five $\mathrm{P}[\mathrm{lac} Z]$ insertions were isolated in a screen of $\sim 6000$ lines. In addition, it was relatively easy $(5$ of 109,000 flies screened; see Materials and methods) to obtain sca alleles in a $\mathbf{P}$ screen. Those alleles recovered in this $\mathrm{P}$ screen that did not contain a P element were found to have deletions around the transcription start site; these deletions probably result from imprecise excision of a P element after its insertion. Moreover, in an independent enhancer trap screen, Bier et al. (1989) recovered 10 insertions (of $\sim 3500$ lines) that also mapped to the position of $s c a$ at 49D1-3 on the second chromosome and displayed the same embryonic expression pattern as we describe for sca (see below; Bier et al. 1989). Thus, sequences around the sca transcription start site appear to be preferentially targeted by P elements.

\section{Expression of sca during development}

A single 3.2-kb sca mRNA species was detected on blots of RNA from embryos (3-12 hr), larvae, and pupae (Fig. 
3); the relative intensity of the signal seen with third-instar imaginal disc RNA and total third-instar larval RNA indicates that larval sca transcripts are highly enriched in imaginal discs. We have analyzed the spatial distribution of sca transcripts by in situ hybridization to embryonic tissue sections and to whole-mount imaginal discs (Figs. 4-6). The $\mathrm{P}[$ lac $Z$ ] lines express $\beta$-galactosidase in a pattern indistinguishable from that of the $s c a$ transcript (cf. respective panels in Figs. 4-6); however, $\beta$-galactosidase is localized to the nucleus in these $\mathrm{P}[$ lacZ) lines (see Materials and methods) and thus can be scored with higher resolution. All of the $\beta$-galactosidase expression patterns described below are based on the A2-6 line; all the other lines appear to have identical expression patterns.

During embryogenesis, sca expression is first detected in the late blastoderm $(\sim 3 \mathrm{hr}$ after fertilization) and becomes more prominent during gastrulation in cells of the neurogenic ectoderm; expression is absent from the mesoderm anlage, the most ventral tissue at the blastoderm stage, and the most anterior and posterior regions of the embyro (Fig. 4A and data not shown). At these stages and throughout most of germ-band extension, sca is found in alternating domains of high and low expression along the anterior-posterior axis (Fig. 4B). By the early extended germ-band stage sca expression is restricted to the neurogenic region, which is the anlage for the nervous system and the ventral ectoderm (Fig. 4B-D). During nervous system development, neuroblasts delaminate from this region and give rise to the central nervous system (CNS), whereas the other cells within this region contribute to the ventral epidermis (Campos-Ortega and Hartenstein 1985). Expression is higher in the neuroblasts (Fig. 4E,F, arrows) than in epidermal precursor cells. Later, sca expression is detected in regions of the ectoderm that will give rise to the PNS (Fig. 4G). After germ-band retraction, high levels of $\beta$-galactosidase were detected in all neuroblasts and neurons of the CNS and the PNS (data not shown) and at weaker levels in most cells of the ventral and lateral epidermis. However, the persistent $\beta$-galactosidase presence is likely due to the stability of the $\beta$-galactosidase fusion protein and not to continuing transcription of the gene,

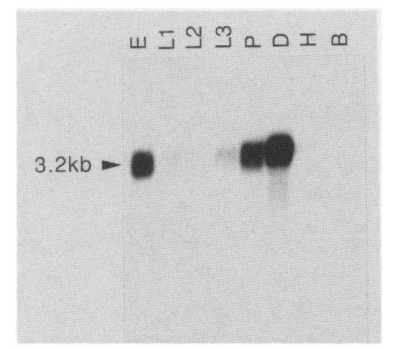

Figure 3. Developmental analysis of $s c a$ transcription. Each lane contains $2 \mu \mathrm{g}$ of poly(A) ${ }^{+}$RNA. (E) Embryos; (L1, L2, and L3) first-, second-, and third-instar larvae, respectively; (P) pupae; (D) total imaginal discs; (H) adult head; (B) adult body. Note that the $s c a 3.2-\mathrm{kb}$ transcript (arrowhead) is mainly transcribed during embryogenesis and during third-instar larval and pupal stages, predominantly in imaginal discs. because we did not detect any endogenous sca mRNA at this stage (data not shown).

In the third-instar larval CNS, we detected sca expression in parts of the optic lobes and in scattered cells within the ventral nerve cord (Fig. $6 \mathrm{H}$ ) and imaginal discs (Figs. 5 and 6). To be able to analyze the transcript distribution in the imaginal discs with satisfactory resolution, we performed whole-mount in situ hybridization using digoxigenin-labeled probes and enzymatic detection (see Materials and methods). sca and the P/lacZ fusion gene in the A2-6 line are expressed in subsets of cells in all imaginal discs. Examples are shown in Figures 5 and 6. In all imaginal discs sca expression is restricted to clusters of cells or single scattered cells. Because the sca phenotype affects mainly eye and bristle development, we have analyzed its expression in detail in the eye imaginal disc during the early stages of eye development and in the wing disc, because the pattern of sensory organs (bristles) it gives rise to in wild type is well characterized.

During eye development sca is expressed mainly in the first photoreceptor to differentiate, $R 8$

Eye development and ommatidial assembly begin in the late third-instar larval period in the eye imaginal disc. During this time the morphogenetic furrow moves across the disc from posterior to anterior. Within this furrow a new column of ommatidia starts to develop approximately every $2 \mathrm{hr}$. These newly emerging ommatidial preclusters are spaced very regularly from their earliest appearance, initiating the highly ordered pattern seen in the adult compound eye (for review, see Tomlinson 1988; Ready 1989). Each ommatidium consists of 20 cells, 8 photoreceptor cells (R1-R8) and 12 accessory cells. The precursor of the R8 photoreceptor cell is the first of these 20 cells to show neuronal differentiation. It is thought that each $\mathrm{R} 8$ precursor cell serves as the founder around which the other photoreceptor precursors are assembled by a series of local inductions (Tomlinson and Ready 1987).

During eye development, sca transcripts and protein accumulate in several cells in each precluster in the morphogenetic furrow and, in one cell, several rows posterior to it (Fig. 5A,B). The sca protein localization within single cells appears to be restricted to vesicles in the apical part of the cell. This is in agreement with the prediction from the $s c a$ sequence that $s c a$ encodes a secreted protein. The expression pattern was analyzed more easily by virtue of the nuclear localization and longer half-life of the $\beta$-galactosidase fusion protein, which was expressed in a very similar pattern (Fig. $5 C-G)$. Low levels of $\beta$-galactosidase were first detected in groups of several nuclei at the anterior edge of the furrow. Higher levels were seen in the second row of $s c a$-expressing cells. The number of nuclei detected in each second-row group varied and was typically around five, although sometimes we detected up to seven. In the third and fourth rows, one nucleus in each group rises to the most apical part of the epithelium and can be seen to be expressing sca more strongly than the surrounding 

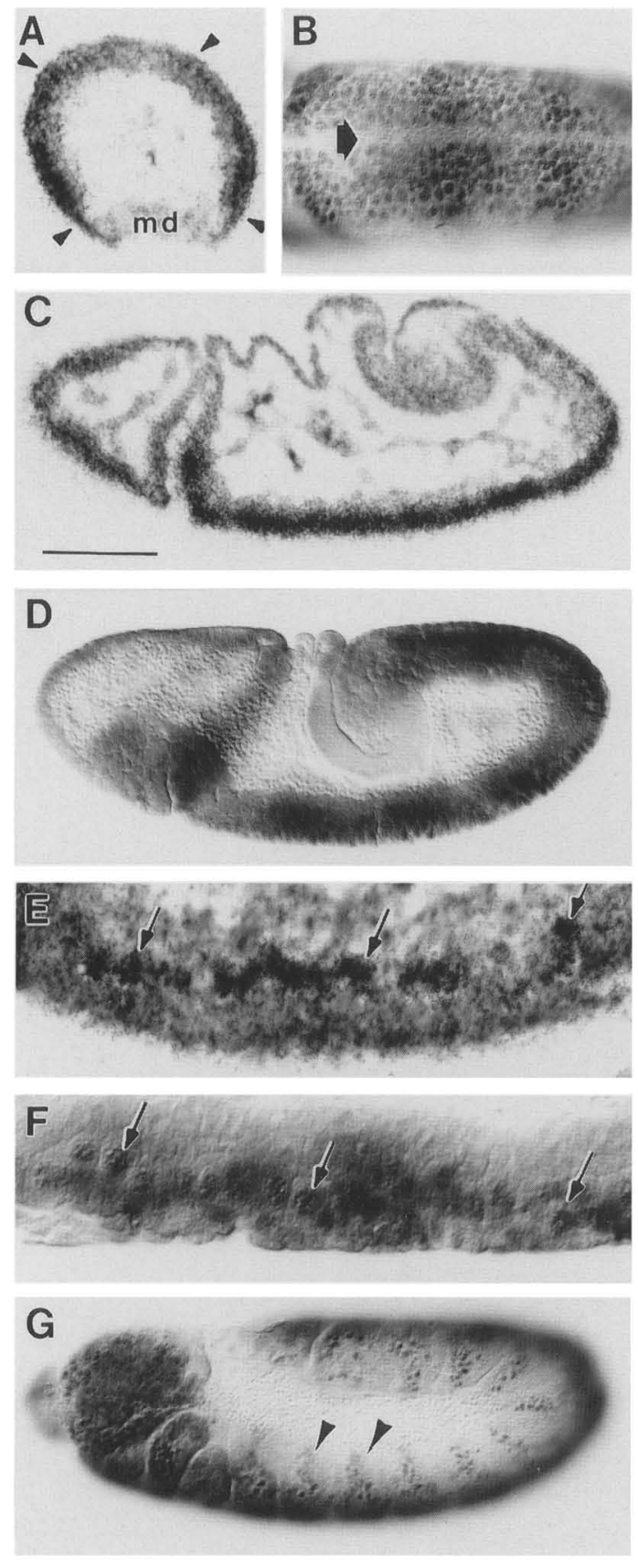

Figure 4. sca expression during embryogenesis. sca expression was detected either by in situ hybridization with $s c a$ antisense RNA to tissue sections $(A, C, E)$ or in whole-mount embryos of the $\mathrm{P}[$ lacZ $]$ line $\mathrm{A} 2-6$ with an anti- $\beta$-galactosidase monoclonal antibody $(B, D, F, G)$. The same expression pattern was also detected with a mouse serum raised against a $\operatorname{trp} E-s c a$ fusion protein (data not shown). Embryos are oriented with anterior to the left (except in the cross section shown in $A$ ) and dorsal up (except in the ventral view shown in $B$ ). Stages of embryogenesis are according to Campos-Ortega and Hartenstein (1985). Bar, $100 \mu \mathrm{m}$ in $C$ and $50 \mu \mathrm{m}$ in $E$ and $F$. (A) Cross section of a gastrulating embryo (stage $6, \sim 3.5 \mathrm{hr}$ after fertilization). sca mRNA is detected as a gradient extending from ventrolateral to dorsal regions (small arrowheads). Note the absence of $s c a$ expression from the ventral mesoderm anlage $(\mathrm{md}) .(B-D)$ sca expression during germ-band extension (stage $8, \sim 4 \mathrm{hr}$ after fertilization). (B) Ventral view of embryo shown in $D$. Note that expression is mainly restricted to the neurogenic ectoderm. The ventral midline is indicated with an arrow. At this and earlier stages, sca expression appears to be modulated in a pair-rule-likemanner (see $B, D)$. $(E, F)$ Higher magnification views of embryos during later germ-band extension (stage $9, \sim 4.5 \mathrm{hr}$ after fertilization). The highest levels of $s c a$ expression were detected in neuroblasts that were delaminating from the neural ectoderm and in these same cells soon thereafter (small arrows). The ectodermal cells express sca at clearly lower levels at this stage. $(G)$ Embryo of stage $11(\sim 7 \mathrm{hr}$ after fertilization). Note expression in ectodermal regions of each segment that will give rise to the PNS (arrowheads) and in head regions. This expression pattern was confirmed by in situ hybridization to the endogenous sca transcripts (data not shown). In A2-6 embryos at stage $14(\sim 10 \mathrm{hr}$ after fertilization), expression of $\beta$-galactosidase was detected mainly in all cells of the CNS and developing PNS and was also still detectable at weaker levels in cells of the ventral and lateral epidermis. No sca mRNA was detected at these later stages (data not shown). nuclei. By the fifth row of expression, now posterior to the morphogenetic furrow, cells were identifiable by their unique position within the precluster (Tomlinson 1985). At this stage the strongly staining apical nucleus can be identified as the R8 nucleus, and levels of $\beta$-galactosidase had lowered in the more basal nuclei. Those still showing detectable expression usually included R2 and R5, sometimes R3 and R4, and occasionally other nearby cells. The identification of these cells was confirmed by double-labeling with an antibody to the sevenless protein, whose expression has been studied by electron microscopy (Tomlinson et al. 1987). sevenless protein expression begins in the fourth row of sca-expressing cells. At earlier stages the arrangement of sca- labeled nuclei varied, and the identities of the scastaining cells within each group was uncertain. It is possible that the groups correspond to some or all of the seven cells that will give rise to the preclusters (R8, R2, R5, R3, R4, M1, and M2; Tomlinson et al. 1987). However, this could not be tested, as the positions of cells that will give rise to the preclusters have not been described. It is not known whether individual cell identities are determined this early. After the fourth row, $\beta$ galactosidase rapidly dropped below the threshold for detection in nuclei other than R8 cells, where it was still present in the posterior part of the disc. This probably reflects, at least in part, the stability of $\beta$-galactosidase in Drosophila cells, as a specific antiserum showed that 
sca protein distribution closely followed that of sca transcripts and was no longer detected after the seventh row (cf. Fig. 5A-C).

\section{sca is expressed in neurogenic regions of the wing disc}

To analyze sca expression in imaginal discs that develop bristles as sensory organs, we have chosen the wing disc, because a fate map of this disc is available (Bryant 1975). Each wing disc gives rise to the heminotum and the wing blade on one side of the fly. The wing margin that separates the ventral and dorsal surfaces of the wing blade is a prominent landmark on the fate map, and the bristles on the anterior wing margin are derived from this region of the disc. No sensory organs are found on the posterior wing margin in wild-type flies. Other landmarks include the positions of macrochaetae precursor cells, which give rise to the large bristles on the notum of adult flies. Both the anterior wing margin bristles and the macrochaetae are among the sensory organs affected by sca mutations (Fig. 1).

In the wing disc, sca is expressed in several patches, as well as in single cells mainly in the anterior compartment of the disc (Fig. 6A-E). Prominent sites of sca expression are two rows of cells in the anterior compartment of the wing blade anlage along the wing margin (Fig. 6A-D, arrowheads) and a patch of cells along the anterior-posterior compartment boundary of the wing
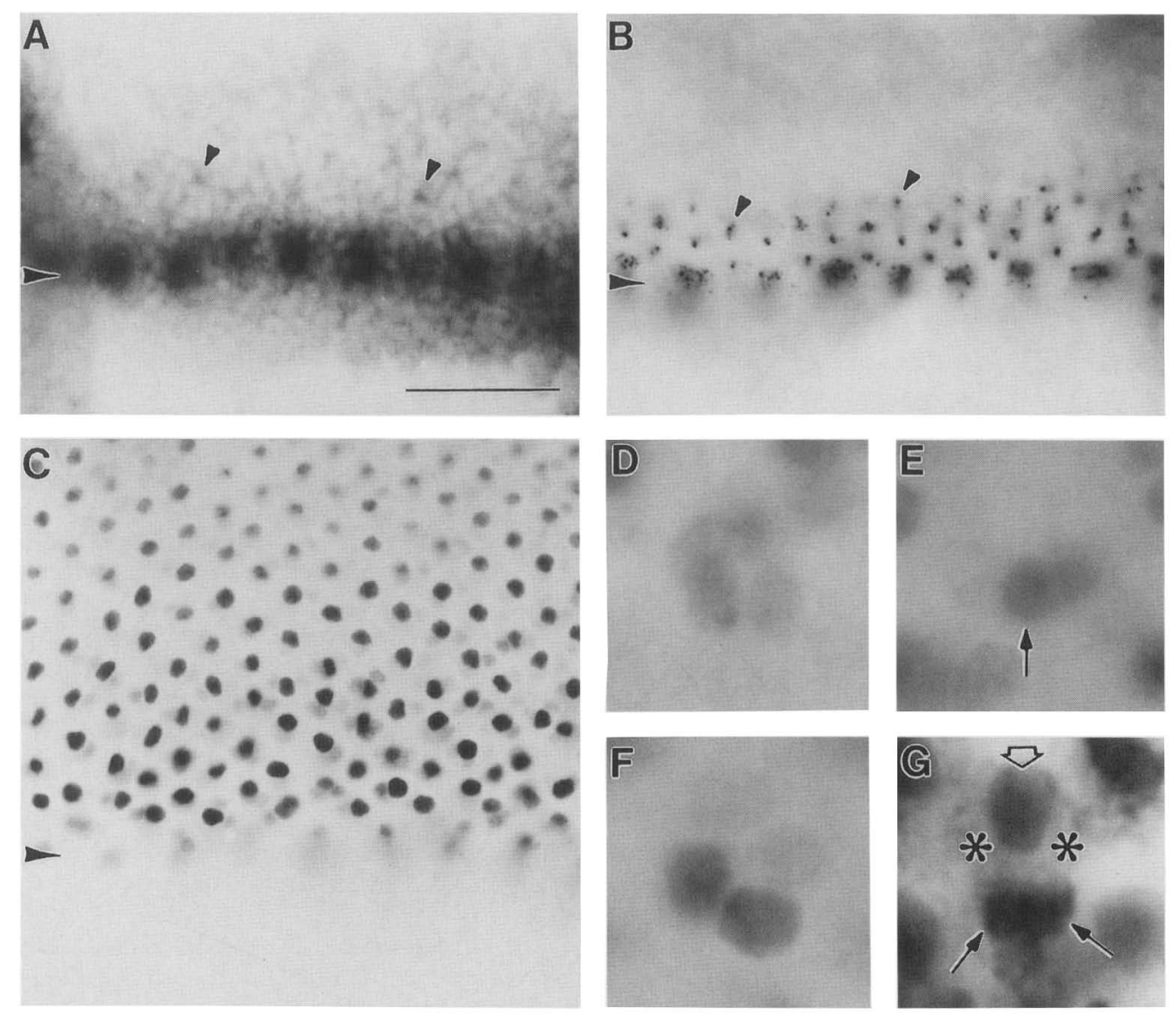

Figure 5. sca expression in the eye imaginal disc. The eye discs are oriented so that posterior is up. The morphogenetic furrow is indicated by an arrowhead. Black bar, $25 \mu \mathrm{m}$ in $A-C$. (A) Eye disc hybridized in situ with a probe complementary to the sca mRNA. $s c a$ is expressed mainly in the morphogenetic furrow in several cells in each precluster and at weaker levels in the first three to four columns posterior to the furrow in one cell (arrowheads). (B) Anti-sca antiserum staining in a wild-type disc. Note initial sca expression in several cells at the anterior edge of the furrow and its restriction to one cell soon thereafter (arrowheads). The same sca anti-serum failed to detect any protein in control discs homozygous for $s c a^{B P 2}$, the transcript null allele (data not shown). $(C) B$-Galactosidase expression in an eye disc of the A2-6 line. Expression starts as in $A$ and $B$ in several cells in each precluster at the anterior edge of the morphogenetic furrow (out of the plane of focus; see $D-F$ ) and becomes restricted to R8 precursor cells. $\beta$-Galactosidase presence in R8 cells in posterior regions of the eye disc is likely due to protein stability, because no sca RNA or protein expression can be detected posterior to the seventh column after onset of $s c a$ expression. $(D-G)$ Higher magnification views of preclusters at early developmental stages in the morphogenetic furrow of disc shown in $C$. $(D)$ sca expression in column 2 . $\beta$-Galactosidase is detectable in several cells with the same intensity. (E) A cluster in next posterior column $(3)$ to one shown in $D$. One cell (arrow) among the initial group of each precluster, usually at the position of the R8 precursor, starts to express $s c a$ at higher levels. $(F)$ Another example of a cell cluster in column 3. In some clusters there are still two cells that express sca at similar levels, perhaps competing to become the R8 precursor. $(G)$ A precluster of the fifth row of the A2-6 disc double-labeled for $\beta$-galactosidase and sevenless protein (sev). Note sev expression in R3 and R4 precursors (small arrows) and $\beta$-galactosidase in R8 (open arrow). The unlabeled R2 and R5 precursors are also visible (asterisks). 

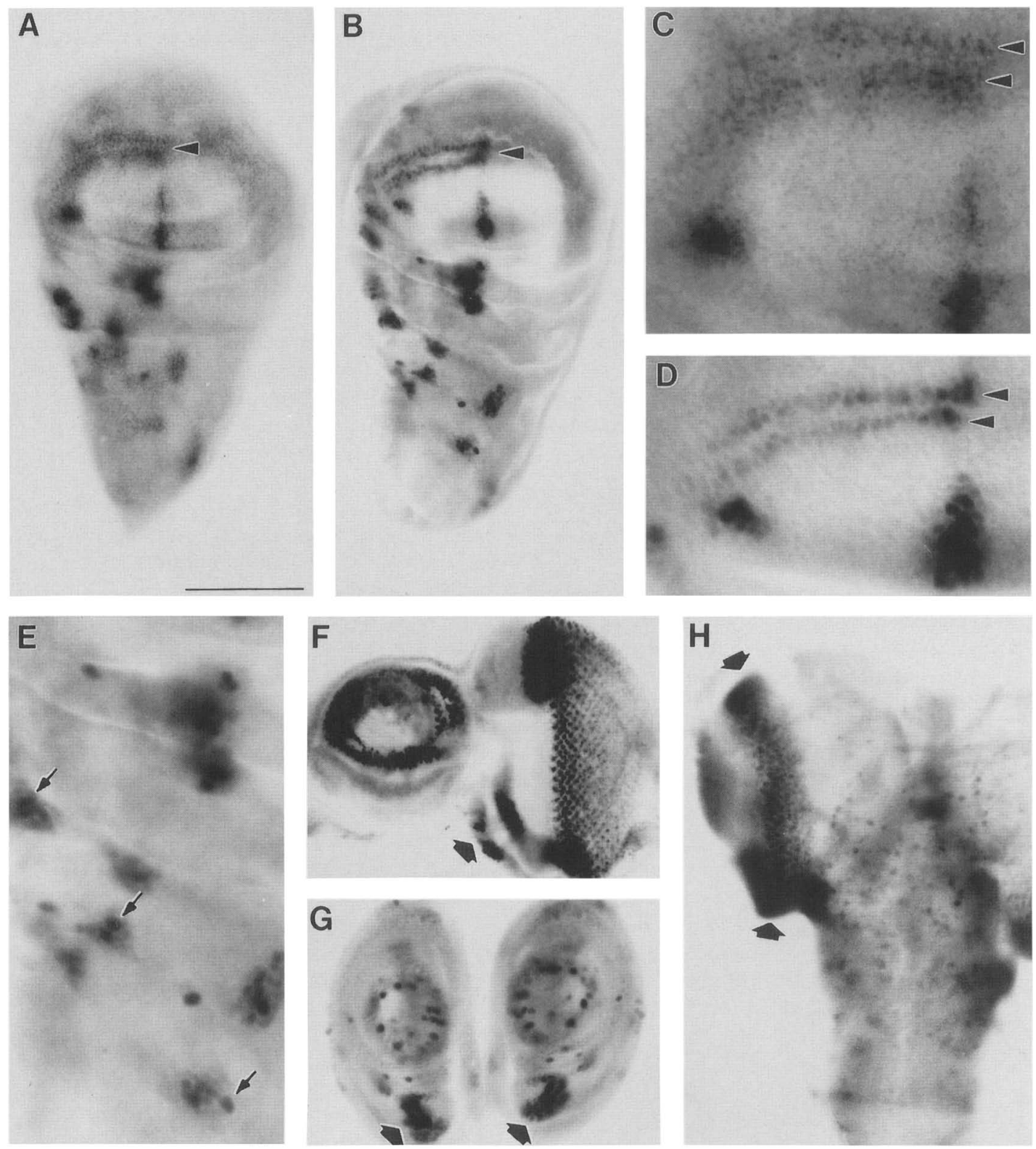

Figure 6. sca expression in imaginal discs and larval CNS. $(A, C)$ Whole-mount in situ hybridization; $(B, D-H) \beta$-galactosidase protein localization in the A2-6 P[lacZ] line. These expression patterns have been confirmed with a mouse serum raised against a trpE-sca fusion protein; see also Fig. 5. $(A-F)$ Anterior to the left; $(H)$ anterior up. Bar in $A$ indicates $100 \mu \mathrm{m}$ for all panels, except $C-E$, where the bar corresponds to $25 \mu \mathrm{m}$. $(A-E)$ sca expression in the wing disc. Note the virtually identical expression patterns as detected by in situ hybridization $(A, C)$ or $\beta$-galactosidase expression $(B, D)$. Two rows of cells expressing sca at the wing margin in the anterior compartment are indicated with arrowheads. $(E)$ Higher magnification view of notum anlage of disc shown in $B$. Note that $s c a$ expression is not uniform within the different cell groups. One (or few) cell(s) express sca at higher levels (small arrows). The discs shown in $A$ and $B$ are from different preparations. $(F, G) s c a$ expression in the eye-antennal imaginal disc and prothoracic leg discs, respectively. Note the difference in patterns between the antennal and the leg discs. $s c a$ is expressed in patches of cells that give rise to parts of the dorsal head surface where the ocelli and several bristles reside $(F$, arrow) and in the imaginal chordotonal organ precursor in the leg discs $(G$, arrows). $(H)$ Expression in the third-instar larval $C N S$; left brain hemisphere and ventral nerve cord are shown. sca expression can be detected in scattered cells throughout the ventral nerve cord and in a region of the optic lobes (arrows).

blade (Fig. 6A-D, arrows), the presumptive anlage of the third wing vein. Within each cluster of $s c a$ expression, one cell (or several) appears to express $s c a$ at higher levels than the surrounding cells (Fig. 6E). The regions/ clusters of $s c a$ expression in the wing disc (Fig. 6A-E) overlap well with the locations of sensory bristle pre- cursors according to the fate map of Bryant (1975). For example, expression is found at the anterior wing margin, which carries several rows of bristles (Fig. $6 \mathrm{~A}-\mathrm{D}$, arrowheads), but not at the posterior margin. Other clusters of $s c a$ expression in the anlage for the notum also coincide with regions that give rise to 
bristles (e.g., macrochaetae) in the adult fly. Thus, sca expression correlates well with the structures that are affected in sca mutants.

The expression patterns in the other imaginal discs have not been analyzed in detail. In the antennal disc sca is expressed in many cells in a circle-like arrangement (Fig. 6F), and in the leg discs expression is restricted to a group of cells in the part of the disc giving rise to proximal structures, most likely overlapping the anlage for the imaginal chordotonal organ (Fig. 6G, arrow; Jan et al. 1985 ), and in circular arrangements of cells in the anlage for the leg (a pair of prothoracic leg discs is shown in Fig. $6 \mathrm{G}$; note that not all sca-expressing cells in the leg anlage are in the plane of focus). Nevertheless, these expression patterns and those observed in other imaginal discs, together with the $s c a$ phenotype, suggest that $s c a$ may be expressed in PNS primordia and sensory organ precursor cells in all imaginal discs.

\section{Ectopic expression of AS-C genes activates sca expression}

Members of the AS-C belong to the "proneural" group of genes that are thought to define the neurogenic regions in imaginal discs (for review, see Ghysen and DamblyChaudiere 1988). Recessive mutations of some of the AS-C genes cause the absence of subsets of bristles, whereas gain-of-function mutations of the same genes cause ectopic development of additional bristles. For the two genes analyzed in this respect, achaete $|a c|$ and scute (sc), the expression patterns in the wing disc (Romani et al. 1989) are very similar to that of $s c a$, including expression on the anterior wing margin, the anlage for the third wing vein, and the macrochaetae precursor positions. $H w^{49 c}$ and $H w^{1}$ are dominant mutations of $s c$ and $a c$, respectively, which lead to their generalized overexpression in the wing disc and to ectopic bristle development (Balcells et al. 1988).

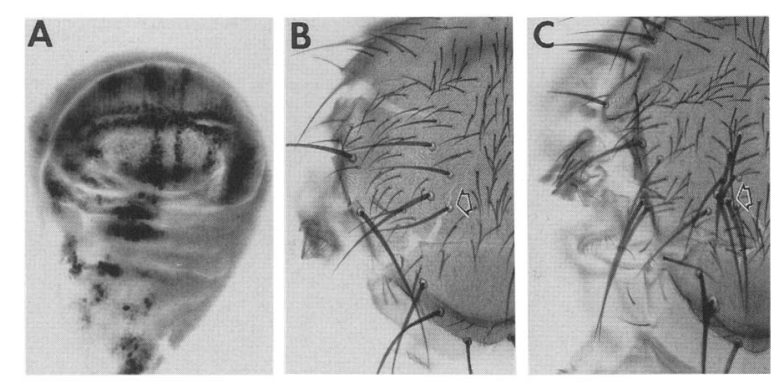

Figure 7. Analysis of $s c a$ in combination with $\mathrm{Hw}$ mutations. (A) $\beta$-Galactosidase protein localization in the A2-6 line in a wing disc from a homozygous $H w^{49 c}$ female (cf. to Fig. $6 \mathrm{~B}$ for wild-type expression pattern). Note widespread sca overexpression in $H w^{49 c}$ disc. Expression is detected in the posterior compartment of the wing blade anlage and in broadened regions in the notum. Nevertheless, certain landmarks, such as the wing margin, are still visible. The nota of the genotypes $H w^{49 c}(B)$ and $H w^{49 c} ; s c a^{B P 2}(C)$ are shown. Note ectopic macrochaetae development in $H w^{49 c}(B$, an example is indicated by the arrow; cf. with wild-type notum shown in Fig. 1C) and the duplication of these ectopic bristles in the double mutant flies $(C)$. An example is indicated by the arrow.
The phenotypes of $a c$ and $s c$ mutations and the expression patterns of these genes are consistent with their controlling sca expression. We asked whether the dominant gain-of-function $s c$ and $a c$ mutations $H w^{49 c}$ and $H w^{1}$ alter $s c a$ expression, using the $\mathrm{P}[1 a c Z] \mathrm{A} 2-6$ line as a marker for $s c a$ expression. In wing discs derived from homozygous $H w^{49 c}$ females carrying one copy of A2-6, $\beta$-galactosidase expression was more widespread than in wild type; sca expression was observed in areas where it is not normally expressed, such as the posterior wing blade anlage (cf. Figs. 6B and 7A). Very similar effects were observed in homozygous $\mathrm{Hw}^{1}$ wing discs (data not shown). This generalized overexpression closely resembles the overexpression of $s c$ and $a c$, as detected by in situ hybridization in the wing discs of the same $H w$ genotypes (Balcells et al. 1988). We did not observe any significant effect of recessive alleles of the same genes on sca expression in the wing disc (data not shown). Thus, the individual loss of $s c$ or $a c$ function does not appear to affect $s c a$ expression. However, we did not examine a $s c^{-}, a c^{-}$double mutant because of the lethality of this genotype.

Double mutant combinations of AS-C alleles and $s c a$ were constructed to test genetically whether $s c a$ acts downstream of AS-C. The recessive alleles were epistatic to sca mutants. That is, the AS-C mutations removed the same sets of bristles with similar penetrance in the absence of $s c a$ function, and the sca phenotype was seen only in the remaining bristles (data not shown). The ectopic bristles produced in the dominant $H w^{49 c}$ allele were often found duplicated in sca mutant homozygotes, both on the dorsal thorax and the wing blade (Fig. $7 \mathrm{~B}$ and $\mathrm{C}$, and data not shown). Both of these results are consistent with $s c a$ acting downstream of the AS-C. In the case of $H w^{49 c}$, they show that the novel sca expression in this genotype functions in restricting neuronal differentiation within ectopic bristle domains, analogous to $s c a$ function in the development of bristles in normal positions.

\section{Discussion}

We have cloned the sca gene, using P-element tagging, and determined the DNA alterations associated with several sca mutations. The sca gene is transcribed into a single 3.2-kb RNA species through much of development; several sca mutations specifically affect this transcription unit. DNA sequence presented elsewhere shows that this locus encodes a putative secreted protein, related to the fibrinogen gene family (N.E. Baker, M. Mlodzik, and G.M. Rubin, in prep.). We have described the pattern of $s c a$ expression in wild type and mutants of the AS-C. Based on these results and the sca phenotype, we propose that the $s c a$ product is involved in defining single neuronal precursors within developing neurogenic regions.

\section{sca expression and neuronal differentiation}

Throughout development we found a correlation between sca transcription and neurogenesis. During early 
embryogenesis, sca is expressed in cells of the ventral neurogenic ectoderm. All of these cells have the potential to develop as neuroblasts, although only a proportion of them do so. Later, sca is expressed again in regions that give rise to the PNS. sca expression also correlates with neurogenesis in imaginal structures. For example, in the wing imaginal disc, neurogenic primordia for the sensory bristles have been defined by a variety of developmental, genetic, and molecular studies. The pattern of $s c a$ expression is consistent with the position of these neurogenic domains. In the developing eye disc, sca is expressed mostly in the R8 photoreceptor cell, which is the first neuron to differentiate and is thought to serve as the foundation for the determination of other cells. Nevertheless, in the morphogenetic furrow, expression occurs initially in several other cells also. Based on the effect of $s c a$ mutations on the positioning of neuronal differentiation in these tissues, as well as the expression in neurogenic regions, we suggest that the sca gene product is normally involved in the process of restricting neuronal differentiation to particular cells within each neurogenic domain, rather like the role that has been proposed for the neurogenic genes.

In all of these cases, it is noteworthy that sca expression is seen initially in more than just those cells that develop as neurons or sensory organ precursors. Because neurons or sensory organs are thought to be specified within each of their respective neurogenic regions by cell interactions among equivalent cells, one possibility is that initially sca expression might be identifying all members of an equivalence group. For the ventral neurogenic ectoderm of the embryo and the bristle primordia of the wing disc, sca expression agrees quite well with the extent of the competent neurogenic regions. It may also be true for the PNS of the embryo and for R8 cell development in the eye disc, where the extent of the competent regions has been less well mapped.

Soon after the initial uniform expression in the neurogenic regions, sca expression increases in specific cells within these regions. The cells expressing sca at high levels are cells that have entered the neural developmental pathway, for example, the neuroblasts in the embryonic CNS or the R8 precursor cells during eye development. Similarly, this is likely to be true for imaginal bristle development; thus, the cells expressing sca at high levels in the neurogenic patches in the wing disc might be already specified, at least partially, as the sensory organ precursors among the respective group of cells.

\section{sca expression and eye development}

In the case of R8 and eye disc development, $s c a$ is not detected initially in all cells at the anterior edge of the furrow, although all of these cells are thought to be equivalent and have the potential to develop as R8 cells. When first detected, $s c a$ already appears to be expressed in a periodic pattern, raising the formal possibility that sca might not be involved in forming the initial periodicity but, rather, in the process of limiting R8 development to one cell of each group. However, we cannot ex- clude the existence of low levels of uniform expression below the threshold level of sensitivity of our detection methods more anterior to where we first detect $s c a$ expression. Moreover, the observed eye disc phenotype (N.E. Baker, M. Mlodzik, and G.M. Rubin, in prep.) indicates that sca plays a role in establishing the initial periodicity, because the spacing of preclusters and, thus, R8 precursors, in mutant eye discs is clearly irregular. Potentially, there may be interactions between forming preclusters and the assembled column immediately posterior. Indeed, the precise positioning of each new row one-half unit out of phase with respect to the last suggests that the existing pattern has an influence and that $s c a$ is involved in this regulation, as judged from its phenotype. Inhibition governed by sca expression in the R8 precursor might extend from the next posterior column, inhibiting sca expression in cells that are closer to the already developing precluster, and thus lead to the observed very regular array of developing ommatidia.

\section{sca encodes a partially redundant function}

The phenotype of mutations suggests that sca function is required in several parts of the nervous system. In the adult, sca mutants affect the number of sensory bristles. The eye appears abnormal externally because the size and number of photoreceptor cells in each facet is variable. The eye phenotype has been attributed to mispositioning of R8 cell development, based both on mosaic analysis and on analysis of early differentiation in the eye disc (N.E. Baker, M. Mlodzik, and G.M. Rubin, in prep.). However, in both cases, the penetrance of the $s c a$ phenotype is not complete. During bristle development only a subset of bristles appears duplicated in each individual animal, although all innervated bristles can be and are affected when a large number of individuals is analyzed together. Similarly, in the morphogenetic furrow not all cells develop as R8 cells. The recently described phenotype of mutations at the shaggy gene lsgg; Simpson and Catheret 1989, originally called zestewhite 3 ) is relevant to this issue. sgg is also thought to be required in limiting neuronal differentiation. However, in the neurogenic regions of the wing imaginal disc, many $\mathrm{sgg}^{-}$cells become sensory organ precursors, so that the sgg phenotype is more extreme than sca. Lossof-function mutations in another gene that appears to be involved in the same process, the neurogenic gene Notch, also display a more severe phenotype than $s c a$, such that all cells in the morphogenetic furrow develop as R8 cells and all cells of each neurogenic region in the wing disc develop as bristles (Dietrich and Campos-Ortega 1984; Cagan and Ready 1989; N.E. Baker, M. Mlodzik, and G.M. Rubin, in prep.).

Nevertheless, it is surprising that even amorphic sca mutations are viable when homozygous and do not have large effects on the formation of the CNS of the embryo (Brand and Campos-Ortega 1990; N.E. Baker, M. Mlodzik, and G.M. Rubin, unpubl.). It is possible that the embryonic expression of $s c a$ has no function or plays some different role that we have been unable to detect. Another possibility is that another gene (or genes) en- 
codes a related function, so that no effect on embryonic neurogenesis results if only sca function is lost. The relative incompleteness of the $s c a$ mutant phenotype, even in the adult, supports the redundancy idea.

\section{Relationship of sca to the AS-C and other genes}

The AS-C contains four related transcription units that are thought to define the extent of neurogenic regions during the development of adult bristles. In the wing disc the expression patterns of two genes of the AS-C, $a c$ and $s c$, closely resemble that of $s c a$ (Romani et al. 1989), and ectopic expression of either of $a c$ or $s c$ caused similar ectopic expression of sca. Consistent with this, double-mutant experiments indicate that $s c a$ is required downstream of $a c$ and $s c$. Given the structural similarity between AS-C genes and the myc class of DNA-binding proteins (Villares and Cabrera 1987; Murre et al. 1989), it seems likely that the AS-C might be responsible for the normal activation of $s c a$ transcription in the bristle primordia. We suppose that as part of the process of generating a neurogenic region, the AS-C activates some genes that promote neuronal differentiation, and others, including $s c a$, that limit it. The final pattern in which only some cells continue to express AS-C genes and become sensory organ precursors would then result from the interactions of these factors. Experiments with the dominant $H w$ mutations support this scheme because novel neurogenic regions resulting from ectopic AS-C expression also require $s c a$ function to limit neuronal differentiation. The observation that either $a c$ or $s c$ function alone is sufficient for activation of sca transcription in ectopic regions of the disc probably explains why the absence of one or the other does not affect sca expression. This is consistent with the observation that $a c$ and $s c$ can actually replace each other for some defined functions (e.g., larval sense organs) and thus encode (partially) redundant proteins (for review, see Ghysen and Dambly-Chaudiere 1988).

A number of other genes have also been implicated in controlling neuronal differentiation in imaginal discs, including $s g g, h, e m c$, and the zygotic neurogenic genes typified by Notch. Simpson and Catheret (1989) have shown that $s g g$ is also downstream of the AS-C and thus could be involved in the same process as $s c a$. In contrast, $h$ and $e m c$ appear to interact negatively with the AS-C genes in a dosage-dependent manner (Moscoso del Prado and Garcia-Bellido 1984; Garcia-Alonso and Garcia-Bellido 1988). The molecular structure of $e m c$ and $h, m y c$ family-like helix-loop-helix proteins lacking the typical basic region required for DNA binding, suggests that these genes interact with $a c$ and $s c$ at the post-translational level by forming heterodimers and thus modifying $a c$ and $s c$ activity (Rushlow et al. 1989; Ellis et al. 1990; Garrell and Modolell 1990). A schematic summary of the genetic hierarchy involved in bristle development is presented in Figure 8. As deduced from previously published data, it appears that $h$ and $e m c$ are first involved in the restriction of the action of the AS-C genes $a c$ and $s c$ to defined regions within the imaginal disc. In these defined neurogenic regions, $a c$ and $s c$ control the differentiation of sensory organs. Cell-cell interactions within each neurogenic group of cells then define one (or several) sensory organ mother cell. This cell would prevent its neighbors from entering the same developmental pathway and would continue to express $a c$ and $s c$. These cell interactions probably involve $s c a, s g g$, and genes of the neurogenic class (Dietrich and Campos-Ortega 1984). Based on the molecular structure of $s c a$, a putative secreted protein, and genetic interactions during eye development, we have suggested that sca may be a ligand for the transmembrane Notch protein (N.E. Baker, M. Mlodzik, and G.M. Rubin, in prep.). This prediction is based on the observation that the split phenotype (spl, an allele of Notch) is suppressed by sca mutations (Brand and Campos-Ortega 1990; Rabinow and Birchler 1990; N.E. Baker, M. Mlodzik, and G.M. Rubin, in prep.). Because the $s p l$ bristle phenotype also depends on sca dosage, sca could encode a ligand for Notch during bristle development as well. Consistent with this hypothesis, the bristle phenotype of $s c a$ is enhanced by heterozygosity for a Notch deletion (N.E. Baker, M. Mlodzik, and G.M. Rubin, unpubl.). This would place Notch downstream of the AS-C as well, consistent with many other studies (for review, see Simpson 1990).

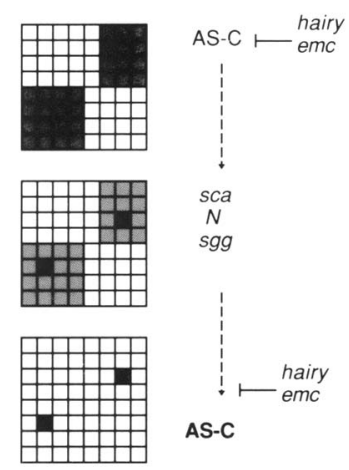

Figure 8. Schematic summary of the genetic hierarchy and interactions that specify bristle development in imaginal discs. The shaded regions represent neurogenic regions within a field of imaginal disc tissue at different developmental stages, as detected by $s c a$ expression in the respective cells. Through cellcell interactions within these domains, single cells are defined to become sensory organ precursor cells (indicated in black). A schematic summary of the genetic interactions during this process is presented. First, expression of AS-C genes, which is negatively regulated by $h$ and $e m c$, defines single neurogenic regions (for review, see Ghysen and Dambly-Chaudiere 1988). The cell-cell interactions within each of these domains, probably involving the products of the $s c a, s g g$ (Simpson and Catheret 1989), Notch ( $N$; Dietrich and Campos-Ortega 1984), and other neurogenic genes (Dietrich and Campos-Ortega 1984; for review, see Simpson 1990), then define a single sensory organ mother cell that continues to express the AS-C genes $a c$ and/or $s c$. Thoughout this process, $h$ and $e m c$ appear to negatively regulate AS-C gene activity (Moscoso del Prado and Garcia-Bellido 1984; Garcia-Alonso and Garcia-Bellido 1988; Ellis et al. 1990; Garrell and Modolell 1990). 


\section{Materials and methods}

Drosophila mutations and chromosomes employed

sca $^{1}$ The original $s c a^{1}$ mutation was isolated by Ives (Morgan et al. 1938) and may have arisen spontaneously. We mapped $s c a^{1}$ meiotically with respect to $w^{+}$transformants of known cytological location. $w$; $s c a^{1} / \mathrm{cn} \mathrm{w}^{+}$females were crossed to $w$; cn $s c a^{T M 4} / B a l$ tester males, and the progeny were screened for $w_{;}(c n) s c a^{1} W^{+} / c n s c a^{T M 4}$ recombinants. The $c n$ mutation allowed the order of the $s c a^{1}$ and $w^{+}$mutations to be determined and provided a standard for normalizing recombination frequency. $s c a^{1}$ mapped right of a $W^{+}$transposon inserted in 49C2-4 (1 recombinant from 4000 chromosomes) and left of a $\mathrm{W}^{+}$transposon in 49D1-3 (3 recombinants from 8000 chromosomes). Based on the frequency of recombinants with $\mathrm{cn}$ in the same crosses, these data suggest that the two $w^{+}$inserts are $\sim 0.25$ map units apart, with the $s c a$ gene between them.

$\mathrm{sca}^{\mathrm{OB} 7}, \mathrm{sca}^{\mathrm{TM} 4}, \mathrm{sca}^{\mathrm{UM} 2}$, and $\mathrm{sca}^{\mathrm{WB} 1}$ Other sca alleles are ethane methyl sulfonic (EMS) acid-induced mutations identified in a screen for homozygous viable mutations affecting the eye (N.E. Baker, K. Moses, D. Nakahara, and G.M. Rubin, unpubl.|. sca ${ }^{B 1}$ was identified among 18,000 EMS-treated sperm (25 mM) by failure to complement $s c a^{1}$. $s c a^{B X 1}$ was identified among 32,000 $\mathrm{X}$-irradiated sperm (4000 rad) by failure to complement $s c a^{1}$. $s c a^{B X 1}$ is associated with In(2R)49C3-D3; 42. (The banding of the 49 region was perturbed near the centromeric breakpoint, preventing a more precise cytological analysis.) $s c a^{K E 3}, s c a^{K E 7}$, $s c a^{K E 15}, s c a^{K E 17}, s c a^{K E 305}$, and $s c a^{K X 2}$ were isolated by Brand and Campos-Ortega (1990) as dominant suppressors of $s p l . s c a^{K X 2}$ is associated with Df(2R)49D1-3; 49F1-2 (Fig. 2A, and data not shown). $s c a^{X L 1}$ was induced by X-irradiation (G. Jurgens, unpubl.).

Hybrid-dysgenesis-induced alleles F2 chromosomes derived from a P-male $\times \mathrm{M}$-female cross were screened for ability to complement sca mutations. $\pi 2$ and $78-61$ were the P strains used (gift from W. Engels). rumpled ${ }^{E B 3} s c a^{1}$ and $s c a^{B 1}$ were used as screening chromosomes. (rumpled is another second chromosome mutation affecting the eye. No dysgenic rumpled mutants were obtained in the 86,000 chromosomes screened this way.) Five independent sca mutations were obtained from a total of 109,000 chromosomes screened. Three of these, called $s c a^{B P 1}, s c a^{B P 2}$, and $s c a^{B P 3}$, were analyzed further. Only $s c a^{B P 1}$ had a $P$ element inserted in 49D1-3. The $s c a^{B P 1}$ mutation was reverted by a further dysgenic cross. $c n s c a^{B P 1} b w / s c a^{1}$ males (all of which were phenotypically mutant for sca) were crossed to $\mathrm{Ball}+$ females derived from a dysgenic cross [78-61 males $\times C y O / I n(2 L R) G L A$ females]. The germ line of the resulting $c n s c a^{B P 1} b w / B a l$ males was screened for reversion events by crossing to $c n s c a^{W B 1} b w / C y O$ tester females. Two revertants, called $s C a^{B P 1}+R B 1$ and $s c a^{B P 1+R B 2}$, were obtained from 2000 chromosomes screened in this way. These revertants both lacked P elements at 49D, as assayed by in situ hybrizations to polytene chromosomes. Other mutations and chromosomes are described in Lindsley and Zimm $(1985,1990)$.

\section{Recombinant DNA}

To recover DNA sequences flanking the P-element insertion point, we constructed a genomic library from the $s c a^{B P 1}$ strain and isolated recombinant phage containing P-element DNA sequences. A Drosophila genomic library (Moses et al. 1989) was then screened with probes made from restriction fragments flanking the P-insertion point. cDNAs were isolated from an eye imaginal disc library (constructed by Alan Cowman), using sequences from -0.67 to $+5.7 \mathrm{~kb}$ (see Fig. 2) by standard procedures.
Plasmid rescue was generally performed as described by Hanahan et al. (1980). DNA was extracted from transformant $\mathrm{P}[$ lacZ] adults as described by Lis et al. (1983). One microgram of genomic DNA was digested with an apropriate restriction enzyme and ligated in a volume of $200 \mu$ l. The ligation reaction was used to transform Escherichia coli strain XL1-Blue (Stratagene). The bacterial cells were made competent according to the standard transformation protocol of Hanahan (1985), except that the cells were grown at $25^{\circ} \mathrm{C}$ rather than $37^{\circ} \mathrm{C}$.

The $\mathrm{P}[$ lacZ $]$ vectors used are as described by Bier et al. (1989) and Wilson et al. (1989), with the white gene as selectable eye color marker. The nuclear localization of the P/lacZ fusion protein is due to amino acid sequences in the amino-terminal region of the $\mathrm{P}$ tranposase.

\section{Sequencing and transcript analysis}

DNA sequence was determined by the chain termination method (Sanger et al. 1977), using Sequenase (U.S. Biochemical Corp.). Templates were made from M13mpl0 vectors containing inserts made by sonication of plasmid DNA or from Bluescript (Stratagene) vectors containing restriction fragments as inserts.

RNA isolation and RNA blots Total RNA from all stages and mass-isolated Oregon- $\mathrm{R}$ third-instar imaginal discs (Eugene et al. 1979) was isolated, as described by Moses et al. (1989), and poly $(\mathrm{A})+$ RNA was selected by oligo(dT) chromatography. Poly $(\mathrm{A})^{+}$RNA ( $2 \mu \mathrm{g}$ each lane) was separated on $1 \%$ agarose $/ 2$ $M$ formaldehyde gels and transferred to nitrocellulose and hybridized following standard procedures. In the case of RNA from sca mutants or $\mathrm{P}[1 a c Z]$ lines, $40 \mu \mathrm{g}$ of total RNA was loaded in each lane.

Primer extension experiments A synthetic oligonucleotide complementary to nucleotides 121-137 (see Fig. 4) was end-labeled with ${ }^{32} \mathrm{P}$ using T4 polynucleotide kinase, annealed to $2 \mu \mathrm{g}$ poly $(\mathrm{A})^{+}$RNA from embryos or discs at $60^{\circ} \mathrm{C}$ for $90 \mathrm{~min}$, and extended at $37^{\circ} \mathrm{C}$ using $\mathrm{AMV}$ reverse transcriptase. The products were analyzed on $6 \%$ polyacrylamide $/ 7.6 \mathrm{M}$ urea gels.

\section{In situ hybridization and immunocytochemistry}

In situ hybridization to whole-mount discs was performed according to the protocol of Tautz and Pfeifle (1989). The imaginal discs were dissected in PBS or mass-isolated, as described by Eugene et al. (1979), and fixed in 4\% paraformaldehyde, and $0.5 \%$ Triton X-100 in PBS for $15-20 \mathrm{~min}$. All incubations and washes were performed at room temperature. After three 5-min washes in PBS, $0.1 \%$ Tween, the discs were digested with proteinase $\mathrm{K}(12.5 \mu \mathrm{g} / \mathrm{ml}$ in PBS, $0.1 \%$ Tween $)$ for $4-10 \mathrm{~min}$. Following digestion, the discs were washed once in PBS, $0.1 \%$ Tween, and $2 \mathrm{mg} / \mathrm{ml}$ glycine for $10 \mathrm{~min}$ and twice for $5 \mathrm{~min}$ each in PBS, $0.1 \%$ Tween, before being fixed for 20 min with $4 \%$ paraformaldehyde and $0.2 \%$ glutaraldehyde in PBS $(\mathrm{H}$. Kramer and L. Zipursky, pers. comm.). Following four 5-min washes in PBS, $0.1 \%$ Tween, the discs were prehybridized and hybridized as described by Tautz and Pfeifle (1989). Nonradioactive probes were made by using digoxigenin-dUTP and detected with a monoclonal antibody against digoxigenin coupled to alkaline phosphatase according to the manufacturer's instructions (Boehringer Mannheim).

In situ hybridization to embryonic tissue sections was performed as described previously (Ingham et al. 1985).

$\beta$-Galactosidase protein was localized immunohistochemically by using an anti- $\beta$-galactosidase monoclonal antibody (Promega, used at $1: 200$ ) and horseradish peroxidase (HRP) histochemistry. The sca antigen was detected with a mouse polyclonal serum (used at $1: 1000$ ) raised against a $\operatorname{trp} E$ fusion pro- 
tein (Koerner et al. 1991) containing 196 amino acids from the carboxyl terminus of the putative sca protein. Fixation and treatment of imaginal discs was done following the procedure of Tomlinson and Ready (1987).

\section{Acknowledgments}

We thank Bill Engels, Luis Garcia Alonso, Michael Brand, and Jose Campos-Ortega for fly stocks, and Lilly and Yuh-Nung Jan for allowing us to screen through some of their enhancer trap lines. We are grateful to Ethan Bier, Yuh-Nung Jan, Michael Brand, and Jose Campos-Ortega for sharing unpublished results, Kevin Moses for helpful suggestions, and Todd Laverty for help with chromosome in situ hybridizations. We also thank Luis Garcia Alonso, Chip Ferguson, Yash Hiromi, Corey Goodman, and members of the Rubin lab for their comments on drafts of this manuscript. This work was supported, in part, by a postdoctoral fellowship from the European Molecular Biology Organization to M.M. and a postdoctoral fellowship from the Damon Runyon-Walter Winchell Cancer Research Fund to N.E.B.

The publication costs of this article were defrayed in part by payment of page charges. This article must therefore be hereby marked "advertisement" in accordance with 18 USC section 1734 solely to indicate this fact.

\section{References}

Balcells, L., J. Modolell, and M. Ruiz-Gomez. 1988. A unitary basis for different hairy-wing mutations of Drosophila melanogaster. EMBO I. 7: 3899-3906.

Bellen, H., C.J. O'Kane, C. Wilson, U. Grossniklaus, R. KurthPearson, and W.J. Gehring. 1989. P-element-mediated enhancer detection: A versatile method to study development in Drosophila. Genes Dev. 3: 1288-1300.

Bier, E., H. Vaessin, S. Shephard, K. Lee, K. McCall, S. Barbel, L. Ackerman, R. Carretto, T. Uemura, E.H. Grell, L.Y. Jan, and Y.N. Jan. 1989. Searching for pattern and mutations in the Drosophila genome with a P-lacZ vector. Genes Dev. 3: $1273-1287$.

Brand, M. and J.A. Campos-Ortega. 1990. Second site modifiers of the split mutation of Notch define genes involved in neurogenesis in Drosophila melanogaster. Roux's Arch. Dev. Biol. 198: 275-285.

Bryant, P.J. 1975. Pattern formation in the imaginal wing disc of Drosophila melanogaster: Fate map, regeneration, and duplication. J. Exp. Zool. 193: 49-78.

Cagan, R.L. and D.F. Ready. 1989. Notch is required for successive cell decisions in the developing Drosophila retina. Genes Dev. 3: 1099-1112.

Campos-Ortega, J.A. and V. Hartenstein. 1985. The embryonic development of Drosophila melanogaster. Springer Verlag, Berlin.

Caudy, M., H. Vaessin, M. Brand, R. Tuma, L.Y. Jan, and Y.N. Jan. 1988. daughterless, a gene essential for both neurogenesis and sex determination in Drosophila, has sequence similarities to myc and the achaete-scute complex. Cell 55: $1061-1067$.

Cavener, D.R. 1987. Comparison of the consensus sequence flanking translational start sites in Drosophila and vertebrates. Nucleic Acids Res. 15: 1353-1361.

Dietrich, U. and J.A. Campos-Ortega. 1984. The expression of neurogenic loci in imaginal epidermal cells of Drosophila melanogaster. I. Neurogenet. 1: 315-332.

Ellis, H.M., D.R. Spann, and J.W. Posakony. 1990. extramacrochaetae, a negative regulator of sensory organ development in Drosophila, defines a new class of helix-loop-helix proteins. Cell 61: 27-38.

Eugene, O.E., M.A. Yund, and J.W. Fristrom. 1979. Preparative isolation and short-term organ culture of imaginal discs of Drosophila melanogaster. Tissue Culture Assoc. Manual 5: $1053-1062$.

Garcia-Alonso, L.A. and A. Garcia-Bellido. 1988. Extramacrochaetae, a trans-acting gene of the achaete-scute complex of Drosophila involved in cell communication. Roux's Arch. Dev. Biol. 197: 328-338.

Garrell, J. and J. Modolell. 1990. The Drosophila extramacrochaetae locus, an antagonist of proneural genes that, like these genes, encodes a helix-loop-helix protein. Cell 61: 3948.

Ghysen, A. and C. Dambly-Chaudiere. 1988. From DNA to form: The achaete-scute complex. Genes Dev. 2: 495-501.

Hanahan, D. 1985. Techniques for transformation of E. coli. In DNA cloning, a practical approach (ed. D.M. Glover), vol. 1, pp. 109-135. IRL Press, Oxford.

Hanahan, D., D. Lane, L. Lipsich, M. Wigler, and M. Botchan. 1980. Characteristics of an SV-40 plasmid recombinant and its movement into and out of the genome of a murine cell. Cell 21: 127-139.

Held, L.I. and P.J. Bryant. 1984. Cell interactions controlling the formation of bristle patterns in Drosophila. In Pattern formation: A primer in developmental biology (ed. G. Malacinsky and S.V. Bryant). pp. 291-322. Macmillan, New York.

Hultmark, D., R. Klemenz, and W.J. Gehring. 1986. Translational and transcriptional control elements in the untranslated leader of the heat-shock gene hsp22. Cell 44: 429-438.

Ingham, P.W., K.R. Howard, and D. Ish-Horowicz. 1985. Transcription pattern of the Drosophila segmentation gene hairy. Nature 318: 439-445.

Jan, Y.N., A. Ghysen, I. Christoph, S. Barbel, and L.Y. Jan. 1985. Formation of neuronal pathways in the imaginal discs of Drosophila melanogaster. I. Neurosci. 5: 2453-2464.

Kidd, S., M.R. Kelley, and M.W. Young. 1986. Sequence of the Notch locus of Drosophila melanogaster: Relationship of the encoded protein to mammalian clotting and growth factors. Mol. Cell. Biol. 6: 3094-3108.

Koerner, T.J., J.E. Hill, A.M. Myers, and A. Tzagoloff. 1991. High-expression vectors with multiple cloning sites for construction of trpE-fusion genes: pATH vectors. Methods Enzymol. (in press).

Kopczynski, C.C., A.K. Alton, K. Fechtel, P.J. Kooh, and M.A.T. Muskavitch. 1988. Delta, a Drosophila neurogenic gene, is transcriptionally complex and encodes a protein related to blood coagulation factors and epidermal growth factor from vertebrates. Genes Dev. 2: 1723-1735.

Lindsley D. and G. Zimm. 1985. The genome of Drosophila melanogaster. Part 1: Genes A-K. Drosophila Inf. Serv. 62.

1990. The genome of Drosophila melanogaster. Part 4: Genes L-Z, Balancers, transposable elements. Drosophila Inf. Serv. 68.

Lis, J., J.A. Simon, and C.A. Sutton. 1983. New heat shock puffs and $\beta$-galactosidase activity resulting from transformation of Drosophila with an hsp $70-1 a c Z$ hybrid gene. Cell 35: 403-440.

Morgan, T.H., C.B. Bridges, and J. Schultz. 1938. Constitution of the germinal material in relation to heredity. Carnegie Inst. Washington Year Book 37: 304-309.

Moscoso del Prado, J. and A. Garcia-Bellido. 1984. Genetic regulation of the achaete-scute complex of Drosophila melanogaster. Roux's Arch. Dev. Biol. 193: 242-245. 
Moses, K., M.C. Ellis, and G.M. Rubin. 1989. The glass gene encodes a zinc-finger protein required by Drosophila photoreceptor cells. Nature 340: 531-536.

Murre, C., P.S. McCaw, and D. Baltimore. 1989. A new DNA binding and dimerization motif in immunoglobulin enhancer binding, daughterless, $M y o D$, and myc proteins. Cell 56: $777-783$

O'Kane, C. and W.J. Gehring. 1987. Detection in situ of genomic regulatory elements in Drosophila. Proc. Natl. Acad. Sci. 84: 9123-9127.

Rabinow, L. and J.A. Birchler. 1990. Interactions of vestigial and scabrous with the Notch locus of Drosophila melanogaster. Genetics 125: 41-50.

Ready, D.F. 1989. A multifaceted approach to neural development. Trends Neurosci. 12: 102-110.

Richelle, J. and A. Ghysen. 1979. Determination of sensory bristles and pattern formation in Drosophila. I. A model. Dev. Biol. 70: 418-437.

Romani, S., S. Campuzano, E.R. Macagno, and J. Modollel. 1989. Expression of acheate and scute genes in Drosophila imaginal discs and their function in sensory organ development. Genes Dev. 3: 997-1007.

Rushlow, C.A., A. Hogan, S.M. Pinchin, K.M. Howe, M. Lardelli, and D. Ish-Horowicz. 1989. The Drosophila hairy protein acts in both segmentation and bristle patterning and shows homology to N-myc. EMBO 1. 8: 3095-3103.

Sanger, F., S. Nicklen, and A.R. Coulson. 1977. DNA sequencing with chain terminating inhibitors. Proc. Natl. Acad. Sci. 74: 5463-5467.

Simpson, P. and C. Catheret. 1989. A study of shaggy reveals spatial domains of acheate-scute allelles on the thorax of Drosophila. Development 106: 57-66.

Simpson, P. 1990. Lateral inhibition and the development of the sensory bristles of the adult peripheral nervous system of Drosophila. Development 109: 509-519.

Tautz, D. and C. Pfeifle. 1989. A non-radioactive in situ hybridization method for the localization of specific RNAs in Drosophila embryos reveals translational control of the segmentation gene hunchback. Chromosoma 98: 81-85.

Tomlinson, A. 1985. The cellular dynamics of pattern formation in the eye of Drosophila. J. Embryol. Exp. Morphol. 89: 313-331.

Tomlinson, A. and D.F. Ready. 1987. Neuronal differentiation in the Drosophila ommatidium. Dev. Biol. 120: 366-376.

Tomlinson, A., D.D.L. Bowtell, E. Hafen, and G.M. Rubin. 1987. Localization of the sevenless protein, a putative receptor for positional information, in the eye imaginal disc of Drosophila. Cell 51: 143-150.

Tomlinson, A. 1988. Cellular interactions in the developing Drosophila eye. Development 104: 183-189.

Vaessin, H., K.A. Bremer, E. Knust, and J.A. Campos-Ortega. 1987. The neurogenic locus Delta of Drosophila melanogaster is expressed in neurogenic territories and encodes a putative transmembrane protein with EGF-like repeats. $E M B O$ I. 6: 3431-3440.

Villares, R. and C.V. Cabrera. 1987. The achaete-scute gene complex of D. melanogaster: Conserved domains in a subset of genes required for neurogenesis and their homology to myc. Cell 50: 413-418.

Wigglesworth, V.B. 1940. Local and general factors in the development of "pattern" in Rhodnius prolixus (Hemiptera). I. Exp. Zool. 17: 180-220.

Wilson, C., R. Kurth-Pearson, H.J. Bellen, C.J. O'Kane, U. Grossniklaus, and W.J. Gehring. 1989. P-element mediated enhancer detection: An efficient method for isolating and characterizing developmentally regulated genes in Drosophila. Genes Dev. 3: 1301-1313.

Wharton, K.A., R.M. Johansen, T. Xu, and S. Artavanis-Tsakonas. 1985. Nucleotide sequence from the neurogenic locus Notch implies a gene product that shares homology with proteins containing EGF-like repeats. Cell 43: 567 581. 


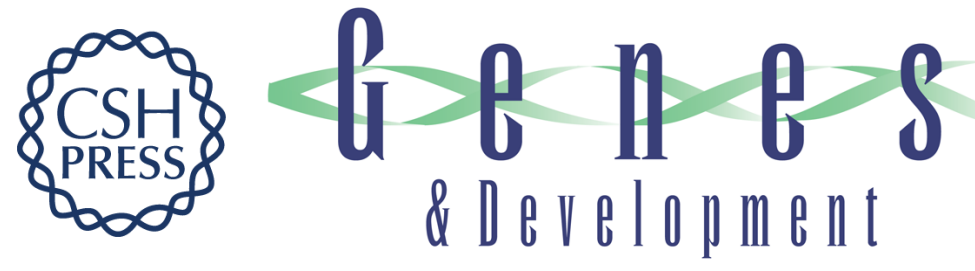

\section{Isolation and expression of scabrous, a gene regulating neurogenesis in Drosophila.}

M Mlodzik, N E Baker and G M Rubin

Genes Dev. 1990, 4:

Access the most recent version at doi:10.1101/gad.4.11.1848

References This article cites 44 articles, 14 of which can be accessed free at:

http://genesdev.cshlp.org/content/4/11/1848.full.html\#ref-list-1

License

Email Alerting

Service

Receive free email alerts when new articles cite this article - sign up in the box at the top right corner of the article or click here.

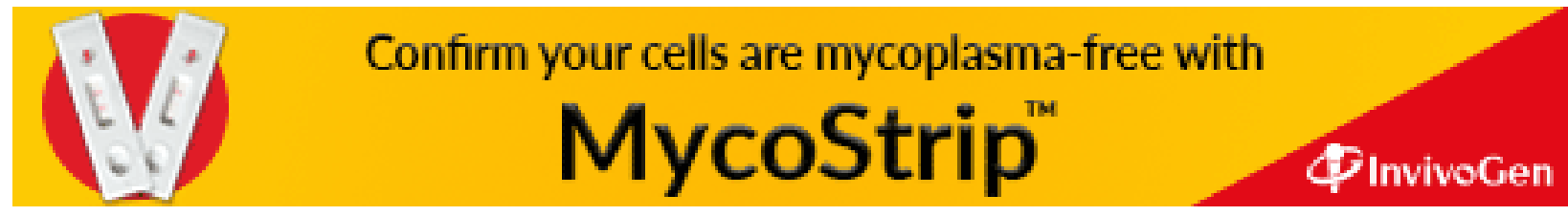

